\title{
Cryogenic D-T Fuel Layers Formed in 1 MM Spheres by Beta-Layering
}

\author{
J. Sater \\ B. Kozioziemski \\ G. W. Collins \\ E. R. Mapoles \\ J. Pipes \\ J. Burmann \\ T. P. Bernat
}

This paper was prepared for submittal to the 40th Annual Meeting of the Division of Plasma Physics New Orleans, LA

November 16-20, 1998

October 15, 1998

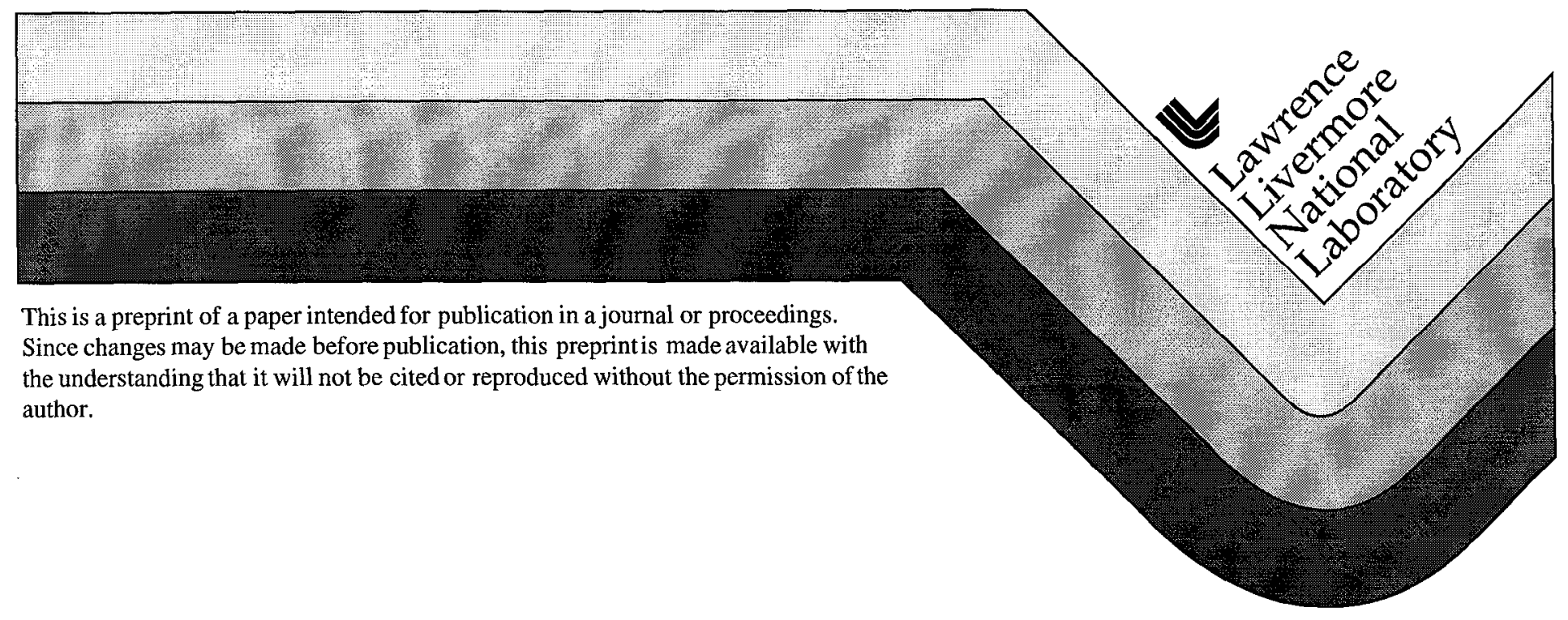




\section{DISCLAIMER}

This document was prepared as an account of work sponsored by an agency of the United States Government. Neither the United States Government nor the University of California nor any of their employees, makes any warranty, express or implied, or assumes any legal liability or responsibility for the accuracy, completeness, or usefulness of any information, apparatus, product, or process disclosed, or represents that its use would not infringe privately owned rights. Reference herein to any specific commercial product, process, or service by trade name, trademark, manufacturer, or otherwise, does not necessarily constitute or imply its endorsement, recommendation, or favoring by the United States Government or the University of California. The views and opinions of authors expressed herein do not necessarily state or reflect those of the United States Government or the University of California, and shall not be used for advertising or product endorsement purposes. 


\title{
CRYOGENIC D-T FUEL LAYERS FORMED IN 1 MM SPHERES BY BETA-LAYERING
}

\author{
J. Sater ${ }^{\dagger}$, B. Kozioziemski ${ }^{\ddagger}$, G.W. Collins ${ }^{\ddagger}$, E.R. Mapoles ${ }^{\ddagger}$, J. Pipes ${ }^{*}$, J. Burmann ${ }^{\dagger}$, T.P. Bernat ${ }^{\ddagger}$ \\ †Schafer Corporation \\ 303 Lindbergh Ave., Livermore, Ca. 94550 \\ *Allied Signal Inc. \\ 2021 Las Positas Ct., Livermore, Ca. 94550 \\ 拈awrence Livermore National Laboratory \\ P.O. Box 808, Livermore, CA 94550
}

\begin{abstract}
Solid D-T fuel smoothly layered on the interior of spherical capsules is required for all inertial confinement fusion ignition target designs. One process for forming these layers, beta-layering, has been studied in surrogate geometries such as open cylinders or tori to allow accurate characterization of the DT surfaces. We present the first results from beta layering in $1 \mathrm{~mm}$ spherical containers, such as will be used in upcoming Omega experiments. These results are also directly relevant to ignition capsules for the National Ignition Facility. We find that layers can form with roughness as small as 1.2 microns rms, and that results are strongly dependent upon freezing rate as well as layer thickness.
\end{abstract}

\section{INTRODUCTION}

All high gain target designs for inertial confinement fusion (ICF) employ uniform layers of condensed DT to achieve efficient ignition of the fuel [1]. Various routes to the formation of these layers within target shells have been investigated [2], and the most promising method relies on the radioactive self heating of condensed DT to redistribute the solid along the isotherms in the fuel container [3], [4], [5]. This process is referred to as "beta layering". The resulting roughness of the ice surface has been characterized optically and been found to be in the range of $1-1.5$ $\mu \mathrm{m}$ RMS for cylindrical layers approximately $100 \mu \mathrm{m}$ thick and $2 \mathrm{~mm}$ in diameter. It is desirable to decrease this roughness to reduce the effects of mix during the implosion of an ICF capsule and increase the drive flexibility available to experimental designers [6].
When liquid DT freezes in an isothermal shell, it initially forms a very rough layer on the bottom of the container. Because the ice heats itself with a volumetric rate of $\mathrm{q}_{s}=5.06 \times 10^{-2} \mathrm{~W} / \mathrm{cm}^{3}$, the surface temperature increases with layer thickness. Thicker areas of the layer are warmer and consequently have higher vapor pressures. Thus, material sublimes away from thick regions and recondenses on thinner areas. If the container is isothermal, this leads to an ice surface that roughly conforms to the container surface. For pure DT, the rate at which the material migrates is $R_{D T}=q_{s} / s \rho_{s}$ [5], where $s$ is the heat of sublimation (1580 $\mathrm{J} / \mathrm{mol})$, and $\rho_{\mathrm{s}}\left(5.03 \times 10^{-2} \mathrm{~mol} / \mathrm{cm}^{3}\right)$ is the density of the solid, so that $1 / R_{\mathrm{DT}}=27$ minutes.

We present our recent results from beta layering in 1 $\mathrm{mm}$ spherical plastic containers. Our results indicate that layers can form with roughness as small as $\mathbf{1 . 2}$ microns rms. We also find that roughness is strongly dependent upon cooling rate and ice layer thickness.

\section{EXPERIMENTAL DETAILS}

Experiments are conducted on a mixture of approximately $25 \% \mathrm{~T}_{2}, 25 \% \mathrm{D}_{2}$, and $50 \% \mathrm{DT}$ which is referred to as D-T. The sample is introduced as a liquid in the normal rotational state. $\mathrm{J}=1$ to $\mathrm{J}=0$ conversion occurs continuously throughout the experiment but no measurements are made of rotational content. Our experimental setup, data collection, and analysis is similar to that described in a recent paper [7].

The main difference is the replacement of a cylindrical sapphire sample cell with a series of $1 \mathrm{~mm}$ diameter plastic 
shells with 10 to $20 \mu \mathrm{m}$ thick walls. The cell is filled with D-T liquid via a fill tube as pictured in Fig. 1. This design allows study of layering in a system very similar to what is required for many ICF target designs.

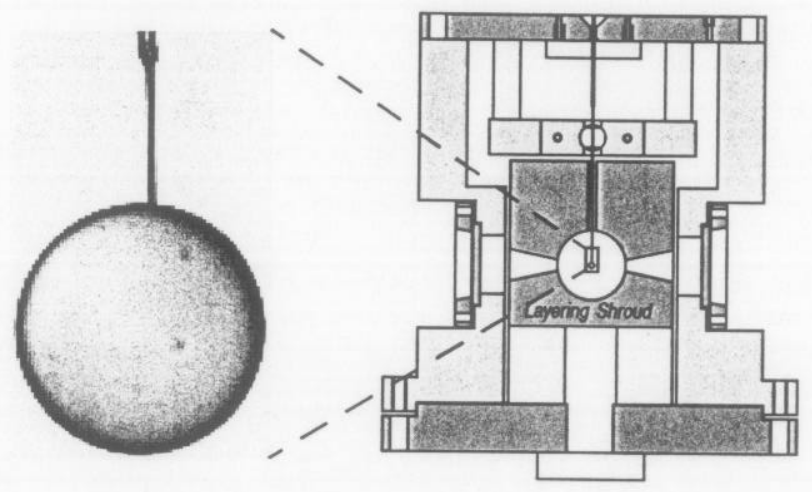

FIGURE 1. Layering occurs in a spherically symmetric geometry

A D-T ice surface conforms to the isotherms shaped by the surrounding layering shroud. Since a smooth spherical shape is desired, the layering shroud is a $25.4 \mathrm{~mm}$ diameter hollow sphere made of OFHC copper shown in Fig. 1. This provides a constant temperature spherical boundary condition. A few torr of ${ }^{4} \mathrm{He}$ gas inside the sphere causes conductive cooling of the plastic shell. The cavity is cooled from the bottom to minimize convection inside the sphere.

The plastic shell is placed at the center of the hollow sphere. A pair of 3 millimeter holes and a pair of 5 millimeter holes are bored in the layering shroud on perpendicular axes to provide a view of the sample cell. They have negligible effect on the spherical isotherms. The shroud is placed inside of a vacuum sealed secondary container.

Temperature is measured by use of calibrated germanium resistance thermometers(GRTs) placed on the top and bottom of the copper cavity. The mean value of the two GRTs is the reported temperature. Temperature stability is better than $2 \mathrm{mK}$ over a period of hours and temperature resolution is $1 \mathrm{mK}$. Calibration has been checked by measuring the triple point of our $\mathrm{D}_{2}$ sample to be $18.72 \mathrm{~K}$ as compared to $18.73 \mathrm{~K}$ reported for $\mathrm{nD}_{2}$ [8].

\section{EXPERIMENTAL RESULTS}

Fig. 2 shows the temperature and RMS surface roughness $\sigma$ evolution during the course of an experiment carried out on a 3 day old sample of DT. $\sigma$ is calculated from modes 2 through 128 . In this experiment we cool slowly through the triple point at a constant rate of $0.5 \mathrm{mK} / \mathrm{min}$ until the set point temperature of $19.78 \mathrm{~K}$ is reached. The temperature is then held constant for a period of time. The DT layer grows during the temperature ramp with a single growth front that begins near the top of the shell. The crystal growth front converges at the bottom of the shell to complete the layer. After formation, $\mathrm{T}=19.78 \mathrm{~K}$, time is 295 minutes, and $\sigma=2.65 \mu \mathrm{m}$. The layer continues to smooth reaching a minimum $\sigma$ of $1.15 \mu \mathrm{m}$ at about 383 minutes. Afterwards the layer roughens. This roughening behavior is not well understood.

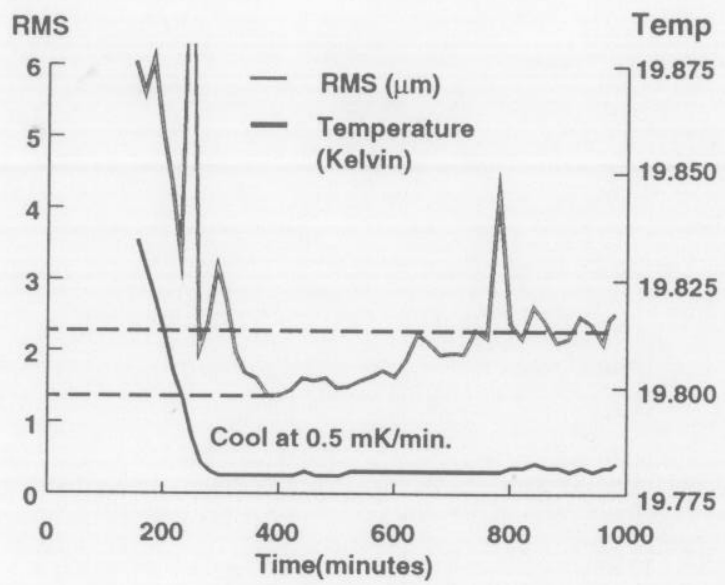

FIGURE 2. We observe that the layer smooths to a minimum value and then roughens with longer times.

Figure 3 shows the power spectral density for the layer at 400 minutes and at 1000 minutes. It is apparent that the layer at 400 minutes is smoother at all mode numbers 
except perhaps at a singular point at mode 7. Most of the difference between the two layers occur in modes 2-4.

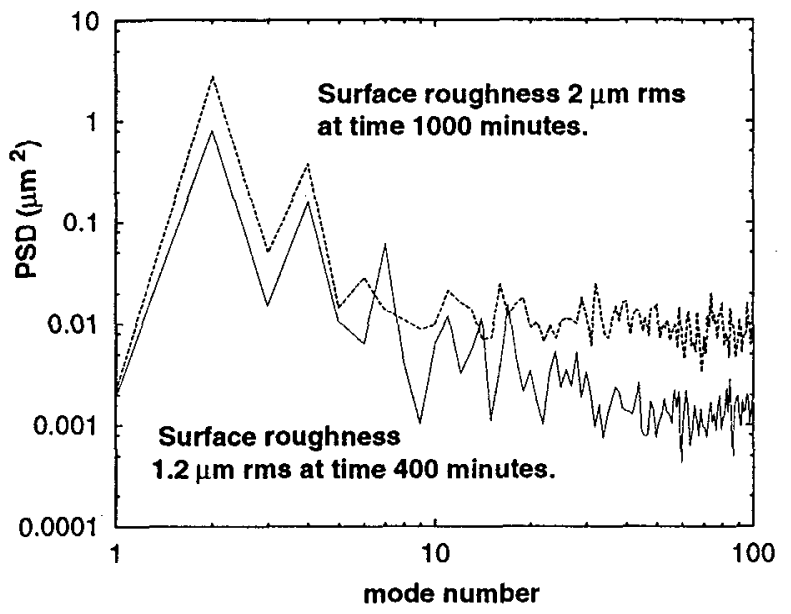

FIGURE 3. Increase in roughness over time after minima is largely due to effects at modal numbers between 2 and 4 though the largest relative increase occurs above mode 20 .

The freezing rate has a strong effect on layer smoothness. $\sigma$ is plotted in Fig. 4 for a series of $210 \mu \mathrm{m}$ layers formed at different freezing rates. For rates slower than $3 \mathrm{mK} / \mathrm{min}$ a dramatically smoother layer is produced. At faster freezing rates, the DT nucleates several small crystals instead of growing with a single front. Layers with several distinctly observable crystals are significantly rougher than those formed from a single nucleation site.

Data indicates that $\sigma$ increases with decreasing layer thickness. In Fig. 5 we have collected all of our layering data with cooling rates between 1 and $2 \mathrm{mK} / \mathrm{min}$ and layer thicknesses between 150 and $225 \mu \mathrm{m}$. The $4.2 \mu \mathrm{m}$ point was for a layer formed at the upper end of the cooling rate. Fig. 6 contains the power spectral density for a $152 \mu \mathrm{m}$ layer and a $220 \mu \mathrm{m}$ layer. The thicker layer is substantially smoother at all mode numbers. This could be due to the observed relative ease that thick layers nucleate as compared to thin layers. A contributing factor is the increase in variation of temperature near the ice/gas interface with thicker layers, i.e. $\delta \mathrm{T}_{\text {bump }}=\mathrm{Qh} \delta \mathrm{h}_{\text {bump }} / \mathrm{k}$. $\delta \mathrm{T}$ is the variation from the average temperature at the ice/gas interface. $\delta \mathrm{h}$ is the variation from the mean ice thickness.

The second type of distinct experiment carried out was a slow continuous freeze through the triple point of DT to a point well below the triple point. In Fig. 7 the temperature vs. time evolution and $\sigma$ vs. time are plotted on the same graph. Here we again observe that the surface reaches a minimum roughness and then at later times becomes quite rough as the layer continues to cool.

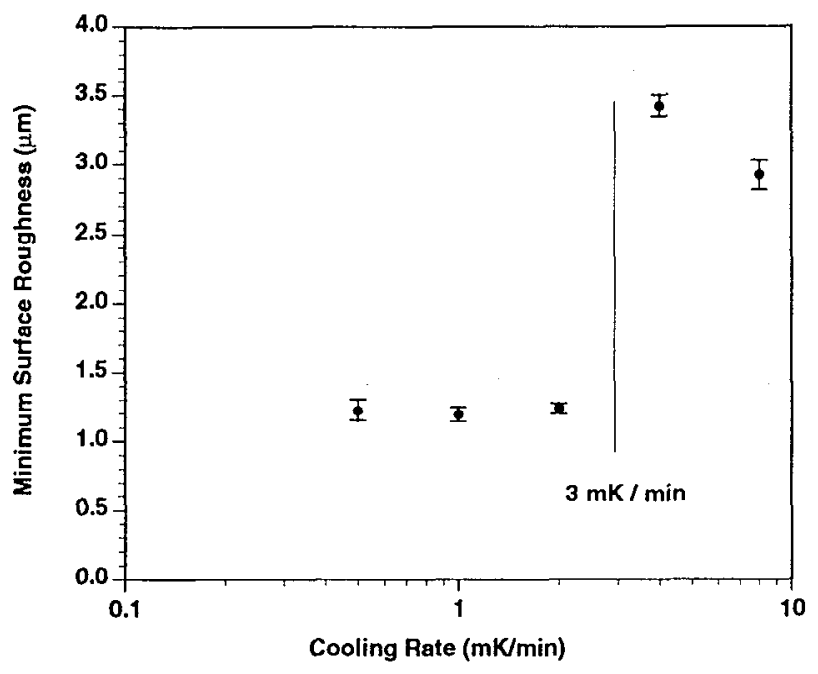

FIGURE 4. Plot of best surface roughness achieved for a series of $210 \mu \mathrm{m}$ layers created with different cooling rates through the triple point of D-T.

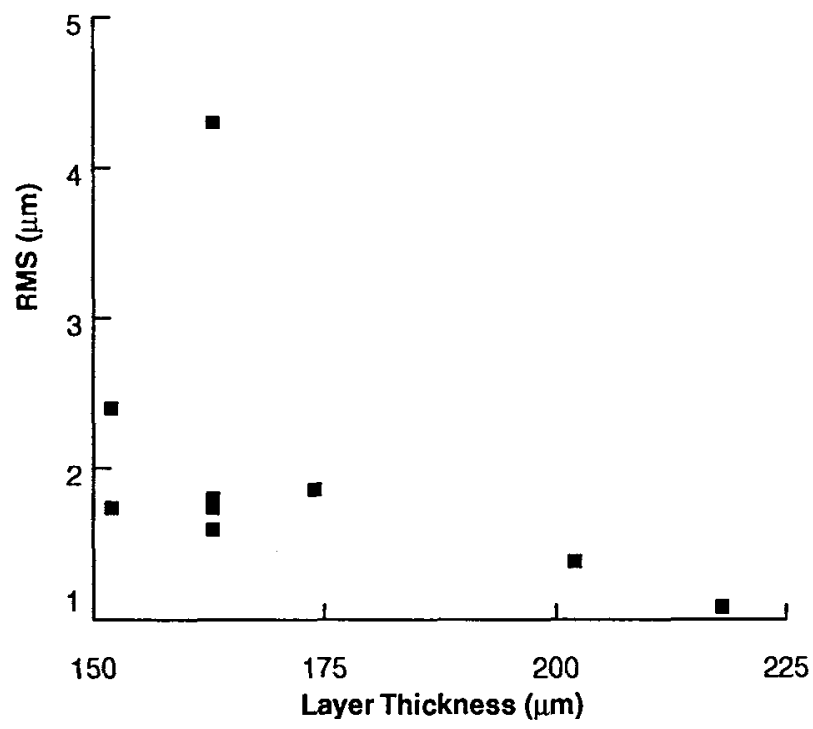

FIGURE 5. Thinner ice layers have a larger $\sigma$. 


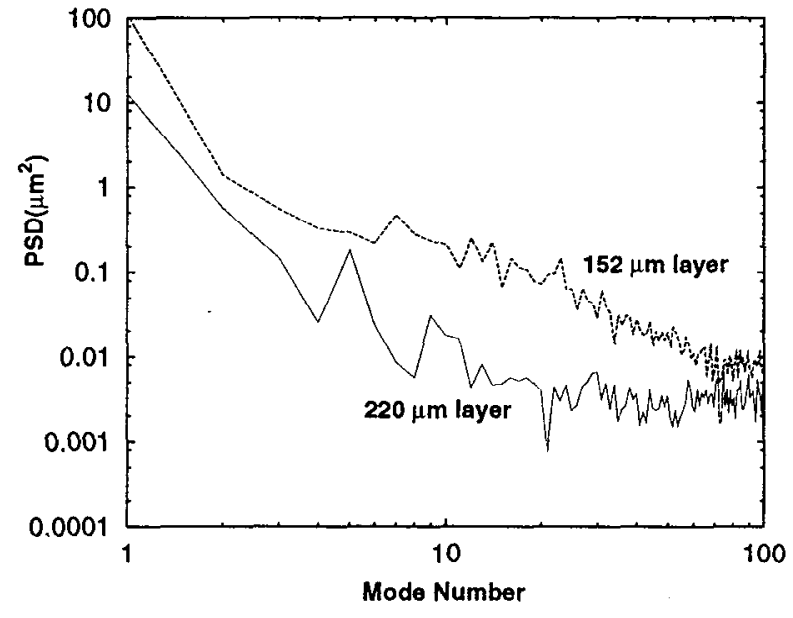

FIGURE 6. The power spectral density plots indicate that a large amount of excess power for the thinner layers are in the middle part of the modal spectrum.

Layers at temperatures below $T_{T P}-0.5 \mathrm{~K}$ are typically rougher than layers produced just below $\mathrm{T}_{\mathrm{TP}}$ Currently, NIF ignition target designs contain $80 \mu \mathrm{m}$ thick D-T layers at $18 \mathrm{~K}$ inside a $2 \mathrm{~mm}$ OD capsule. Our best DT layers are produced just below $T_{\mathrm{TP}}$ at about $19.7 \mathrm{~K}$. The gas density inside of the capsule is $\rho_{\text {gas }}=0.7 \mathrm{mg} / \mathrm{cc}$ instead of the specified $\rho_{\text {gas }}=0.3 \mathrm{mg} / \mathrm{cc}$, and thus would change the convergence of the ignition capsule design.

\section{THEORY}

The equilibrium ice layer minimizes the total free energy at constant volume. The thermal gradient resulting from the tritium decay heating favors uniform layers, however, the anisotropic surface energy favors facets. The curved shell geometry prevents the layer from having a single low energy facet exposed along the entire surface, and any recrystallization to reorient the surface is limited by grain boundary energy. We can model each of these energies to understand the layer roughness.

The total free energy per unit length is expressed as:

$$
E_{T}=\int_{A} \operatorname{C\rho TdA}+\sum_{i}^{n} \gamma^{i} L_{i}+\sum_{i} \gamma_{g b}{ }^{i} t_{i},
$$

where $C$ is the specific heat, $\rho$ is the ice density, $\gamma_{s}$ is the orientation dependent surface energy, $L$ is the length of the crystal facet, $\gamma_{g b}$ is the grain boundary energy, $t$ is the grain boundary length, and $\mathrm{A}$ is the bulk ice area perpendicular to the cylindrical axis.

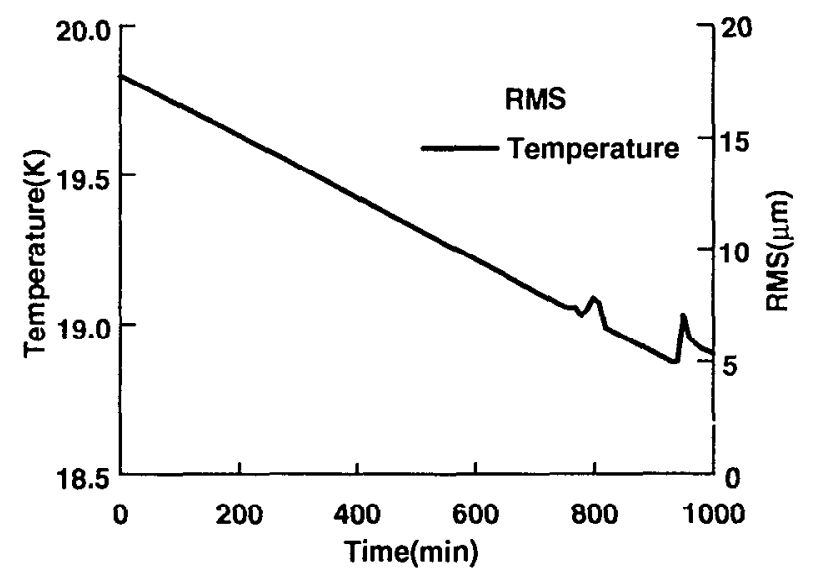

FIGURE 7. With a continuous freeze we also observe that the layer reaches a minimum $\sigma$ early and then degrades.

The $\mathrm{c}$ - facet for solid deuterium was determined to have $\gamma=6 \times 10^{-3} \mathrm{~J} / \mathrm{m}^{2}$ [9]. The best estimate for $\gamma_{\mathrm{gb}}=0.6 \mathrm{x}$ $10^{-3} \mathrm{~J} / \mathrm{m}^{2}, 10$ percent of the surface energy [10]. Using a one dimensional heat flow model for a layer with cylindrical geometry and $n$ regular low energy facets, we find $n=$ 53 minimizes the free energy for a $210 \mu \mathrm{m}$ layer. The corresponding rms surface roughness is 0.15 microns. The model predicts the rms surface roughness decreases with increasing layer thickness out to 300 microns for a $1 \mathrm{~mm}$ shell, consistent with the data in Fig. 5. ${ }^{\mathrm{a}}$ The magnitude of the predicted roughness is a factor of 10 smaller than the data and is due to the highly idealized nature of the model. A more detailed model should include multiple crystal orientations and grain boundary energies.

${ }^{a}$ It should be noted that DT experiences a $12 \%$ shrinkage when cooling through the triple point. Thus a $1 \mathrm{~mm}$ capsule full of liquid at just above the triple point would have a uniform solid layer $253 \mu \mathrm{m}$ thick just below the triple point temperature. 


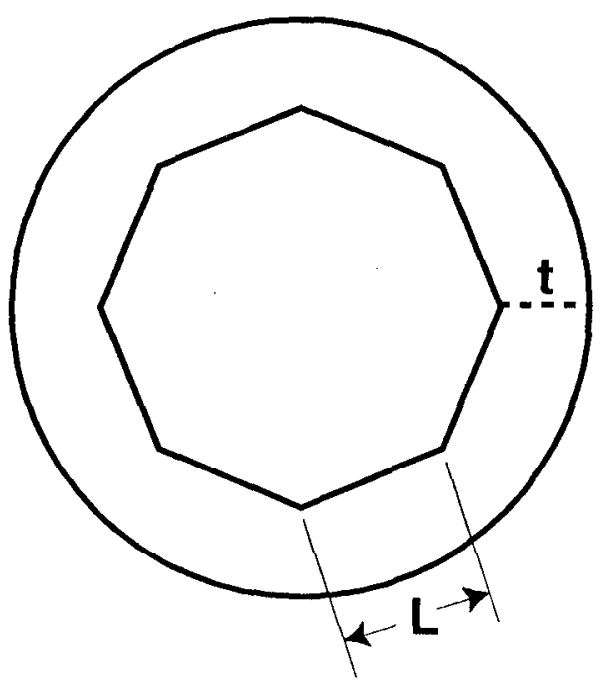

FIGURE 8. Simplified crystal geometry in a DT ice layer. $L$ is length of a single crystal facet. $t$ is crystal thickness.

\section{CONCLUSIONS}

We have presented the first results from beta layering in $1 \mathrm{~mm}$ plastic shells with fill tubes. Our best beta layers have a roughness as small as 1.2 microns rms for a $210 \mu \mathrm{m}$ thick ice layer. Layer smoothness depends upon cooling rate as well as layer thickness. Our best D-T ice layers are formed when freezing through the triple point is slower than $3 \mathrm{mK} / \mathrm{min}$. for $210 \mu \mathrm{m}$ layers. Data and simple calculations indicate that thinner layers are rougher layers.

\section{ACKNOWLEDGMENTS}

Work performed under the auspices of the U.S. Department of Energy by the Lawrence Livermore National Laboratory under contract number W-7405-ENG-48 and by Schafer Corporation under contract number DE-AC03-95SF20732

\section{REFERENCES}

[1] John Lindl, "Development of the indirect-drive approach to inertial confinement fusion and the target physics basis for ignition and gain," Phys. Plasmas 2 (11), 3393 (1995)

[2] K. Kim, L. C. Mok, M. J. Erlenborn, and T. P. Bernat, "Non contact thermal gradient method for fabrication of uniform cryogenic inertial fusion target," $J$. Vac. Sci. Technol. A. 1(2), p. 1196. (1985)

[3] J. R. Miller, Los Alamos Scientific Laboratory Report LA-6245-PR, Dec. 1975, p. 82; Methods and Apparatus for Producing Cryogenic Inertially Driven Fusion Targets, $\mathrm{U}$. S. Patent 4,292,340 (Jan. 1987)

[4] A. J. Martin, R. J. Simms, and D. L. Musinski, KMS Fusion, Inc. Report No. 1348 (1985, unpublished); A. J. Martin, R. J. Simms, and R. B. Jacobs, J. Vac. Sci. Technol. A 6 (3), 1885. (1988)

[5] J. K. Hoffer and L. R. Foreman, Phys. Rev. Lett. 60, 1310 (1988).

[6] S. Hann, S. Pollaine, J. Lindl, et al., ICF Quarterly Report 3(2), Lawrence Livermore National Laboratory, Livermore, CA, UCRL-LR-105821-95-4, p. 81, (1995).

[7] E. R. Mapoles, J. Sater, J. Pipes, E. Monsler, "Smoothing of deuterium-tritium ice by electrical heating of the saturated vapor", Phys. Rev. E. 55, 3473 (1997)

[8] P. Clark Souers, Hydrogen Properties for Fusion Energy, (University of California Press, Berkeley, Ca. 1986), p. 61.

[9] B. J. Kozioziemski, G. W. Collins, T. P. Bernat, "Crystal Growth and Roughening of Solid $\mathrm{D}_{2}$ ", Fusion Technology 31, 482 (1997).

[10] W. W. Mullins, "Theory of Thermal Grooving", Journal of Applied Physics. 28, 333 (1957) 